\title{
Thermodynamic Reference Database (THEREDA) - Present activities
}

\author{
HElge C. MOOG ${ }^{1}$, FrANK BOK ${ }^{2}$, DANIELA FREYER ${ }^{3}$,
} XAVIER GAONA ${ }^{4}$, TRES THOENEN ${ }^{5}$

${ }^{1}$ GRS gGmbH, Theodor-Heuss-Str. 4, 38122 Braunschweig, helge.moog@grs.de (corresponding author)

${ }^{2}$ Helmholtz-Zentrum Dresden-Rossendorf, Institut für Ressourcenökologie, Bautzner Landstraße 400, 01328 Dresden, f.bok@hzdr.de

${ }^{3}$ Technische Universität Bergakademie Freiberg, Institut für Anorganische Chemie, Fakul-tät für Chemie und Physik, Leipziger Straße 29, 09596 Freiberg, daniela.freyer@chemie.tu-freiberg.de

${ }^{4}$ Karlsruher Institut für Technologie, Institut für Nukleare Entsorgung (INE), Hermann-von-Helmholtz-Platz 1, 76344 Eggenstein-Leopoldshafen, xavier.gaona@kit.edu

${ }^{5}$ Paul Scherrer Institut, Laboratory for Waste Management (LES), Forschungsstrasse 111, 5232 Villigen PSI, Switzerland, tres.thoenen@psi.ch

The THEREDA project [1] aims at providing an extensive thermodynamic database for the modeling of solubility equilibria in aqueous solutions within the context of nuclear waste disposal. Focus is laid on saline solutions, typically with an ionic strength $>1 \mathrm{M}$, using the Pitzer approach [2].

THEREDA is operated by five research institutions. A web-based user interface is used for data capture and documentation. The primary products, however, are ready-touse data files for PHREEQC, Geochemist's Workbench, CHEMAPP, and (to a limited extent) EQ3/6. In addition, a code-independent, generic format (JSON) is available for download. Before release, data sets are subject to rigid, internal checks. More than 200 test calculations are used to continously ensure the correctness of calculated results, both in terms of earlier test runs and between different codes.

While extending the database, experimental data for various chemical systems are recorded. The agreement with model calculations using THEREDA are documented. This "positive list" is continously being extended. Generally, covered systems include oceanic salts, actinides, fission products and other elements relevant for nuclear waste disposal

In response to the limited lifetime of existing codes and to extend our user base, efforts are undertaken to support two additional codes, GEMS and TOUGHREACT.

[1] H. C. Moog et al. (2015): Appl. Geochem. (55) 72-84.

[2] K. S. Pitzer (1991): Activity Coefficients in Electrolyte Solutions (2nd ed.). CRC Press. 